\title{
Robust Heteroscedasticity Consistent Covariance Matrix Estimator based on Robust Mahalanobis Distance and Diagnostic Robust Generalized Potential Weighting Methods in Linear Regression
}

M. Habshah

Universiti Putra Malaysia, habshahmidi@gmail.com

Muhammad Sani

Federal University, Dutsin-Ma, sanimksoro@gmail.com

Jayanthi Arasan

Universiti Putra Malaysia, jayanthi@upm.edu.my

Follow this and additional works at: https://digitalcommons.wayne.edu/jmasm

Part of the Applied Statistics Commons, Social and Behavioral Sciences Commons, and the Statistical Theory Commons

\section{Recommended Citation}

Habshah, M.; Sani, Muhammad; and Arasan, Jayanthi (2018) "Robust Heteroscedasticity Consistent Covariance Matrix Estimator based on Robust Mahalanobis Distance and Diagnostic Robust Generalized Potential Weighting Methods in Linear Regression," Journal of Modern Applied Statistical Methods: Vol. 17 : Iss. 1, Article 17. DOI: $10.22237 /$ jmasm/1530279855

Available at: https://digitalcommons.wayne.edu/jmasm/vol17/iss1/17 


\section{Robust Heteroscedasticity Consistent Covariance Matrix Estimator based on Robust Mahalanobis Distance and Diagnostic Robust Generalized Potential Weighting Methods in Linear Regression}

\author{
M. Habshah \\ Universiti Putra Malaysia \\ Selangor, Malaysia
}

\author{
Muhammad Sani \\ Federal University Dutsin-Ma \\ Dutsin-Ma, Nigeria
}

\author{
Jayanthi Arasan \\ Universiti Putra Malaysia \\ Selangor, Malaysia
}

The violation of the assumption of homoscedasticity and the presence of high leverage points (HLPs) are common in the use of regression models. The weighted least squares can provide the solution to heteroscedastic regression model if the heteroscedastic error structures are known. Based on Furno (1996), two robust weighting methods are proposed based on HLP detection measures (robust Mahalanobis distance based on minimum volume ellipsoid and diagnostic robust generalized potential based on index set equality (DRGP(ISE)) on robust heteroscedasticity consistent covariance matrix estimators. Results obtained from a simulation study and real data sets indicated the DRGP(ISE) method is superior.

Keywords: Linear regression, robust HCCM estimator, ordinary least squares, weighted least squares, high leverage points

\section{Introduction}

Ordinary least squares (OLS) is a widely used method for analyzing data in multiple regression models. The homoscedasticity assumption (i.e., equal variances of the errors) is often violated in most empirical analyses. As a result, the error variances tend to be heteroscedastic (unequal variances of the errors). Although OLS is still unbiased, its estimates become inefficient and will not provide reliable inference due to the inconsistency of the variance-covariance matrix estimator.

The commonly used estimation strategy for a heteroscedasticity of unknown form is to perform OLS estimation, and then employ a heteroscedasticity consistent

doi: 10.22237/jmasm/1530279855 | Accepted: August 11, 2017; Published: June 29, 2018.

Correspondence: Muhammad Sani, sanimksoro@gmail.com 


\section{MANI ET AL}

covariance matrix (HCCM) estimator denoted by HC0 (see White, 1980). It is consistent under both homoscedasticity and heteroscedasticity of unknown form. The weakness of the HCO estimator is it is biased in finite samples (MacKinnon \& White, 1985; Cribari-Neto \& Zarkos, 1999; Long \& Ervin, 2000; Rana, Midi, \& Imon, 2012). MacKinnon and White (1985) proposed another HCCM estimator referred to as HC1 and HC2. Davidson and MacKinnon (1993) slightly modified $\mathrm{HC} 2$ and named it HC3; it is closely approximated to the jackknife estimator. Cribari-Neto (2004) proposed another HCCM estimator where the residuals were adjusted by a leverage factor and called it HC4. Cribari-Neto, Souza, and Vasconcellos (2007) proposed HC5, wherein the exponent used in HC4 was modified to consider the effect of maximal leverage.

HCCM estimators are constructed using the OLS residuals vector. In the presence of outliers in the $X$-direction or high leverage points (HLPs), the coefficient estimates and residuals are biased. As a consequence, the inference becomes misleading. Furno (1996) proposed the robust heteroscedasticity consistent covariance matrix (RHCCM) in order to reduce the biased caused by leverage points. Residuals of a weighted least squares (WLS) regression were employed, where the weights were determined by the leverage measures (hat matrix) of the different observations. Lima, Souza, Cribari-Neto, and Fernandes (2009) built on Furno's procedure based on least median of squares (LMS) and least trimmed squares (LMS) residuals. A shortcoming of Furno's method is, in the presence of HLPs, the variances tend to be large resulting to unreliable parameter estimates which is due to the effect of swamping and masking of HLPs. The main reason for this weakness is the use of the hat matrix in determining the weight of the RHCCM algorithm of Furno (1996). Peña and Yohai (1995) showed swamping and masking results from the presence of HLPs in linear regression. It is evident that the hat matrix is not very successful in detecting HLPs (Habshah, Norazan, \& Imon, 2009). Consequently, less efficient estimates are obtained by employing an unreliable method of detecting HLPs. Furno's work has motivated us to use a weight function based on a more reliable diagnostic measure for the identification of HLPs.

In this study, two new robust weighting methods are proposed based on HLPs detection measures; robust Mahalanobis distance based on minimum volume ellipsoid (RMD(MVE)) and diagnostic robust generalized potential based on index set equality (DRGP(ISE)) of Lim and Habshah (2016). The weights determined by DRGP(ISE) are expected to successfully down weight all HLPs. The DRGP(ISE) technique has been proven to be very successful in down weighting HLPs with low 


\section{ROBUST HCCM ESTIMATORS}

masking and swamping effects and less computational complexity, and the algorithm is very fast compared to DRGP(MVE).

\section{Heteroscedasticity Consistent Covariance Matrix (HCCM) Estimators}

Consider a regression model

$$
\mathbf{y}=\mathbf{X} \boldsymbol{\beta}+\boldsymbol{\varepsilon}
$$

where $\mathbf{y}$ is an $n \times 1$ vector of responses, $\mathbf{X}$ is an $n \times p$ matrix of independent variables, $\boldsymbol{\beta}$ is a vector of regression parameters, and $\boldsymbol{\varepsilon}$ is the $n$-vector of random errors. For heteroscedasticity the errors are such that $\mathrm{E}\left(\varepsilon_{i}\right)=0, \operatorname{var}\left(\varepsilon_{i}\right)=\sigma_{i}{ }^{2}$ for $i=1, \ldots, n$, and $\mathrm{E}\left(\varepsilon_{i} \varepsilon_{s}\right)=0$ for all $i \neq s$. The covariance matrix of $\boldsymbol{\varepsilon}$ is given as $\boldsymbol{\Phi}=\operatorname{diag}\left\{\sigma_{i}{ }^{2}\right\}$. The ordinary least squares (OLS) estimator of $\boldsymbol{\beta}$ is $\hat{\boldsymbol{\beta}}=\left(\mathbf{X}^{\prime} \mathbf{X}\right)^{-1} \mathbf{X}^{\prime} \mathbf{y}$, which is unbiased, with the covariance matrix given by

$$
\operatorname{cov}(\hat{\boldsymbol{\beta}})=\left(\mathbf{X}^{\prime} \mathbf{X}\right)^{-1} \mathbf{X}^{\prime} \mathbf{\Phi} \mathbf{X}\left(\mathbf{X}^{\prime} \mathbf{X}\right)^{-1}
$$

However, under homoscedasticity, $\sigma_{i}^{2}=\sigma^{2}$ which implies $\boldsymbol{\Phi}=\sigma^{2} \mathbf{I}_{n}$, where $\mathbf{I}_{n}$ is the $n \times n$ identity matrix. The covariance matrix $\operatorname{cov}(\hat{\boldsymbol{\beta}})=\sigma^{2}\left(\mathbf{X}^{\prime} \mathbf{X}\right)^{-1}$ is estimated by $\hat{\sigma}^{2}\left(\mathbf{X}^{\prime} \mathbf{X}\right)^{-1}$ (which is inconsistent and biased under heteroscedasticity), and $\hat{\sigma}^{2}=\hat{\boldsymbol{\varepsilon}}^{\prime} \hat{\boldsymbol{\varepsilon}} / n-p, \hat{\boldsymbol{\varepsilon}}=\left(\mathbf{I}_{n}-\mathbf{H}\right) \mathbf{y}$, where $\mathbf{H}$ is an idempotent and symmetric matrix known as a hat matrix, leverage matrix, or weight matrix (according to different authors). The hat matrix $(\mathbf{H})$ is defined as $\mathbf{H}=\mathbf{X}\left(\mathbf{X}^{\prime} \mathbf{X}\right)^{-1} \mathbf{X}^{\prime}$, and it plays great role in determining the HLPs in regression model. The diagonal elements hi $=x_{i}\left(x^{\prime} x\right)^{-1} x_{i}^{\prime}$ for $i=1, \ldots, n$ of the hat matrix are the values for leverage of the $i^{\text {th }}$ observations.

White (1980) proposed the most popular HCCM estimator, known as HC0, where he replaced the $\sigma_{i}^{2}$ with $\hat{\varepsilon}_{i}^{2}$ in the covariance matrix of $\hat{\boldsymbol{\beta}}$, i.e.

$$
\mathrm{HCO}=\left(\mathbf{X}^{\prime} \mathbf{X}\right)^{-1} \mathbf{X}^{\prime} \hat{\mathbf{\Phi}}_{0} \mathbf{X}\left(\mathbf{X}^{\prime} \mathbf{X}\right)^{-1}
$$




\section{MANI ET AL}

where, $\hat{\mathbf{\Phi}}_{0}=\operatorname{diag}\left\{\hat{\varepsilon}_{i}^{2}\right\} . \mathrm{HC} 0, \mathrm{HC} 1, \mathrm{HC} 2$, and HC3 are generally biased for small sample size (see Furno, 1997; Lima et al., 2009; Hausman \& Palmer, 2012). This paper will focus only on HC4 and HC5. The HC4 proposed by Cribari-Neto (2004) was built under $\mathrm{HC} 3$, and is defined as follows:

$$
\mathrm{HC} 4=\left(\mathbf{X}^{\prime} \mathbf{X}\right)^{-1} \mathbf{X}^{\prime} \hat{\mathbf{\Phi}}_{4} \mathbf{X}\left(\mathbf{X}^{\prime} \mathbf{X}\right)^{-1}
$$

where

$$
\hat{\boldsymbol{\Phi}}_{4}=\operatorname{diag}\left\{\frac{\hat{\varepsilon}_{i}^{2}}{\left(1-h_{i}\right)^{\delta_{i}}}\right\}
$$

for $i=1, \ldots, n$ with $\delta_{\mathrm{i}}=\min \left\{4, h_{i} / h\right\}$, which control the discount factor of the $i^{\text {th }}$ squared residuals, given by the ratio between $h_{i}$ and the average values of the $h_{i}(h)$. Note that $\delta_{i}=\min \left\{4, n h_{i} / p\right\}$. Since $0<1-h_{i}<1$ and $\delta_{i}>0$ it follows that $0<\left(1-h_{i}\right)^{\delta_{i}}<1$. The larger $h_{i}$ is relative to $h$, the more the HC4 discount factor inflates the $i^{\text {th }}$ squared residual. The truncation at 4 amounts to twice what is used in the definition of HC3; that is, $\delta_{i}=4$ when $h_{i}>4 h=4 p / n$. The result obtained by Cribari-Neto (2004) suggested HC4 inference in finite sample size relative to HC3.

Similarly, another modification of the exponent $\left(1-h_{i}\right)$ of HC4 was proposed by Cribari-Neto et al. (2007) to control the level of maximal leverage. The estimator was called HC5 and defined as

$$
\mathrm{HC} 5=\left(\mathbf{X}^{\prime} \mathbf{X}\right)^{-1} \mathbf{X}^{\prime} \hat{\boldsymbol{\Phi}}_{5} \mathbf{X}\left(\mathbf{X}^{\prime} \mathbf{X}\right)^{-1}
$$

where

$$
\hat{\boldsymbol{\Phi}}_{5}=\operatorname{diag}\left\{\frac{\hat{\varepsilon}_{i}^{2}}{\sqrt{\left(1-h_{i}\right)^{\alpha_{i}}}}\right\}
$$

for $i=1, \ldots, n$ with

$$
\alpha_{i}=\min \left\{\frac{h_{i}}{h}, \max \left\{4, \frac{k h_{\max }}{h}\right\}\right\}
$$




\section{ROBUST HCCM ESTIMATORS}

which determine how much the $i^{\text {th }}$ squared residual should be inflated, given by the ratio between $h_{\max }$ (maximal leverage) and $h$ (mean leverage value of the $h_{i}$ ), and $k$ is a constant $0<k<1$ and was suggested to be chosen as 0.7 by Cribari-Neto et al. (2007) following simulation results that lead to efficient quasi- $t$ inference. When $h_{i} / h \leq 4$ it follows that $\alpha_{i}=h_{i} / h$. Also, since $0<1-h_{i}<1$ and $\alpha_{i}>0$, it similarly follows that $0<\left(1-h_{i}\right)^{\alpha_{i}}<1$.

\section{Robust HCCM Estimators}

The problems of heteroscedasticity and high leverage points were addressed by Furno (1996) to reduce the bias caused by the effect of leverage points in the presence of heteroscedasticity. It was suggested to use weighted least squares (WLS) regression residuals instead of the OLS residuals used by White (1980) in HCCM estimator. The weight is based on the hat matrix $\left(h_{i}\right)$ and the robust (weighted) version of $\mathrm{HCO}$ is defined as

$$
\mathrm{HCO}_{\mathrm{W}}=\left(\mathbf{X}^{\prime} \mathbf{W} \mathbf{X}\right)^{-1} \mathbf{X}^{\prime} \mathbf{W} \hat{\boldsymbol{\Phi}}_{0 \mathrm{~W}} \mathbf{W} \mathbf{X}\left(\mathbf{X}^{\prime} \mathbf{W} \mathbf{X}\right)^{-1}
$$

where $\mathbf{W}$ is an $n \times n$ diagonal matrix with

$$
w_{i}=\min \left(1, \frac{c}{h_{i}}\right)
$$

and $c$ is the cutoff point $c=1.5 p / n, p$ being the number of parameters in a model including the intercept and $n$ the sample size, and $\hat{\boldsymbol{\Phi}}_{0 \mathrm{~W}}=\operatorname{diag}\left\{\tilde{\varepsilon}_{i}^{2}\right\}$ with $\tilde{\varepsilon}_{i}$ being the $i^{\text {th }}$ residuals from weighted least squares (WLS). Note that non-leveraged observations are weighted by 1 and leveraged observations are weighted by $c / h_{i}$ to reduce their intensity; $w_{i}$ is considered to be the weight in this WLS regression, so that the WLS estimator of $\boldsymbol{\beta}$ is

$$
\tilde{\boldsymbol{\beta}}=\left(\mathbf{X}^{\prime} \mathbf{W} \mathbf{X}\right)^{-1} \mathbf{X}^{\prime} \mathbf{W} \mathbf{y}
$$

The robust HCCM estimator for HC4 and HC5, based on Furno's weighting method considered by Lima et al. (2009), are $\mathrm{HC} 4_{\mathrm{w}}$ and $\mathrm{HC} 5_{\mathrm{w}}$, defined as 


$$
\begin{aligned}
& \mathrm{HC} 4_{\mathrm{W}}=\left(\mathbf{X}^{\prime} \mathbf{W X}\right)^{-1} \mathbf{X}^{\prime} \mathbf{W} \hat{\boldsymbol{\Phi}}_{4 w} \mathbf{W} \mathbf{X}\left(\mathbf{X}^{\prime} \mathbf{W X}\right)^{-1} \\
& \mathrm{HC} 5_{\mathrm{W}}=\left(\mathbf{X}^{\prime} \mathbf{W} \mathbf{X}\right)^{-1} \mathbf{X}^{\prime} \mathbf{W} \hat{\boldsymbol{\Phi}}_{5 w} \mathbf{W} \mathbf{X}\left(\mathbf{X}^{\prime} \mathbf{W} \mathbf{X}\right)^{-1}
\end{aligned}
$$

where

$$
\hat{\boldsymbol{\Phi}}_{4 \mathrm{~W}}=\operatorname{diag}\left\{\frac{\tilde{\varepsilon}_{i}^{2}}{\left(1-h_{i}^{*}\right)^{\delta_{i}^{*}}}\right\}, \quad \hat{\boldsymbol{\Phi}}_{5 \mathrm{~W}}=\operatorname{diag}\left\{\frac{\tilde{\varepsilon}_{i}^{2}}{\sqrt{\left(1-h_{i}^{*}\right)^{\alpha_{i}^{*}}}}\right\}
$$

for $i=1, \ldots, n$, with

$$
\delta_{i}^{*}=\min \left\{4, \frac{h_{i}^{*}}{h^{*}}\right\}, \quad \alpha_{i}^{*}=\min \left\{\frac{h_{i}^{*}}{h^{*}}, \max \left\{4, \frac{k h_{\max }^{*}}{h^{*}}\right\}\right\}
$$

and $h_{i}^{*}$ is the $i^{\text {th }}$ diagonal element of the weighted hat matrix $\mathbf{H}_{\mathrm{W}}=\sqrt{\mathbf{W}} \mathbf{X}\left(\mathbf{X}^{\prime} \mathbf{W} \mathbf{X}\right)^{-1} \mathbf{X}^{\prime} \sqrt{\mathbf{W}}$. In this paper the Furno's weighted least square for RHCCM estimation method is denoted by WLSF.

\section{New Proposed Robust HCCM Estimators}

Consider the idea of Furno's RHCCM estimation on two new weighting methods based on HLPs identification measures: robust Mahalanobis distance based on minimum volume ellipsoid (RMD(MVE)) and diagnostic robust generalized potential based on index set equality (DRGP(ISE)). These two methods are very successful in identifying correct HLPs in a data set.

\section{Robust HCCM Estimator based on RMD(MVE)}

Mahalanobis (1936) introduced a diagnostic measure of the deviation of a data point from its center named Mahalanobis distance (MD), in which the independent variables of the $i^{\text {th }}$ observations are presented as $\mathbf{x}_{i}=\left(1, x_{i 1}, x_{i 2}, \ldots, x_{i k}\right)=\left(1, \mathbf{R}_{i}\right)$ so that $\mathbf{R}_{i}=\left(x_{i 1}, x_{i 2}, \ldots, x_{i k}\right)$ will be a $k$-dimensional row vector, where the mean and covariance matrix vector 


\section{ROBUST HCCM ESTIMATORS}

$$
\overline{\mathbf{R}}=\frac{1}{n} \sum_{i=1}^{n} \mathbf{R}_{i}, \quad \mathbf{C V}=\frac{1}{n-1} \sum_{i=1}^{n}\left(\mathbf{R}_{i}-\mathbf{R}\right)^{\prime}\left(\mathbf{R}_{i}-\overline{\mathbf{R}}\right)
$$

respectively. The MD for the $i^{\text {th }}$ point is given as

$$
\mathrm{RMD}_{i}=\sqrt{\left(\mathbf{R}_{i}-\overline{\mathbf{R}}\right)^{\prime}(\mathbf{C V})^{-1}\left(\mathbf{R}_{i}-\overline{\mathbf{R}}\right)}, \quad i=1,2, \ldots, n
$$

Leroy and Rousseeuw (1987) recommended a cutoff point for $\mathrm{MD}_{i}$ as $\sqrt{\chi_{k, 0.5}^{2}}$ and any observation that exceeds this cutoff point is considered to be a HLP. Imon (2002) suggested another cutoff point ( $c d$ ) for $\mathrm{RMD}_{i}$ given by

$$
c d=\operatorname{median}\left(\mathrm{RMD}_{i}\right)+3 \mathrm{MAD}\left(\mathrm{RMD}_{i}\right)
$$

where, MAD stands for median absolute deviation. Since the average vector $\overline{\mathbf{R}}$ and covariance matrix CV are not robust, Rousseeuw (1984) recommended using a minimum volume ellipsoid (MVE) estimator of $\overline{\mathbf{R}}$ and the corresponding $\mathbf{C V}$ which the ellipsoid produced. This technique of MVE is to produce the smallest volume ellipsoid among all the ellipsoids of at least half of the data. The MVE estimator of the average vector is $\mathrm{T}(\mathbf{X})=$ center of the MVE covering at least $h$ points of $\mathbf{X}$ for $h \geq(n+k+1) / 2$, where $k$ is the number of explanatory variables (Rousseeuw \& Driessen, 1999). The corresponding $\mathbf{C V}$ is provided by the ellipsoid and multiplied by a suitable factor in order to obtain consistency. The weight obtained by this $\mathrm{RMD}(\mathrm{MVE})$ method is given by

$$
w_{i r}=\min \left(1, c d / \mathrm{RMD}_{i}\right)
$$

so that, HLPs are weighted by $\left(c d / \mathrm{RMD}_{i}\right)$ and non-leverage by 1 . To obtain the RHCCM estimator based on RMD(MVE) weighting method denoted by WLSRMD, we replace equation (7) by (12) and adopt Furno's RHCCM estimation method as discussed above.

\section{Robust HCCM estimator based on DRGP(ISE)}

The diagnostic robust generalized potential based on minimum volume ellipsoid (DRGP(MVE)) was proposed by Habshah et al. (2009). It has been shown that this method is very successful in the detection of multiple HLPs in linear regression. 


\section{MANI ET AL}

The method consists of two steps where suspects HLPs are identified in the first step by employing RMD based on MVE. The calculation of MVE involves a lot of computational effort. Due to this, the calculation of DRGP based on RMD-MVE takes too much computing time. As such, Lim and Habshah (2016) proposed an improvised DRGP based on index set equality (ISE) in order to reduce the computational complexity of the algorithm. The ISE was tested and found to execute much faster in the estimation of robust estimators of scale and location. Thus, ISE has faster running time compared to MVE (Lim \& Habshah, 2016). They replaced the MVE estimator with the ISE to form DRGP(ISE).

Index set equality (ISE) was developed from the fast minimum covariance determinant (MCD) proposed by Rohayu (2013). The ISE idea is to denote the index set that corresponds to the sample of items in $\mathbf{H}_{\text {old }}$ when their Mahalanobis distance squares are arranged in ascending order by $\mathrm{IS}_{\text {old }}=\left\{\pi_{(1)}^{\text {old }}, \pi_{(2)}^{\text {old }}, \ldots, \pi_{(h)}^{\text {old }}\right\}$ and the corresponding index set of the sample items in $\mathbf{H}_{\text {new }}$ by $\mathrm{IS}_{\text {new }}=\left\{\pi_{(1)}^{\text {new }}, \pi_{(2)}^{\text {new }}, \ldots, \pi_{(h)}^{\text {new }}\right\}$, where $\pi$ is a permutation on $\{1,2, \ldots, n\}$. The steps to compute ISE are as follows:

Step 1: Arbitrarily selecting a subset $\mathbf{H}_{\text {old }}$ containing different $h$ observations.

Step 2: Compute the average vector $\overline{\mathbf{R}}_{\mathbf{H}_{\text {old }}}$ and covariance matrix $\mathbf{C V}_{\mathbf{H}_{\text {old }}}$ for all observations belonging to $\mathbf{H}_{\text {old. }}$.

Step 3: Compute $d_{\text {old }}^{2}(i)=\left(\mathbf{R}_{i}-\overline{\mathbf{R}}_{\mathbf{H}_{\text {old }}}\right)^{\prime} \mathbf{C V}_{\mathbf{H}_{\text {old }}}^{-1}\left(\mathbf{R}_{i}-\overline{\mathbf{R}}_{\mathbf{H}_{\text {old }}}\right)$ for $i=1,2, \ldots, n$.

Step 4: Arrange $d_{\text {old }}^{2}(i)$ for $i=1,2, \ldots, n$ in ascending order, i.e. $d_{\text {old }}^{2}(\pi(1)) \leq d_{\text {old }}^{2}(\pi(2)) \leq \ldots \leq d_{\text {old }}^{2}(\pi(n))$

Step 5: Construct $\mathbf{H}_{\text {new }}=\left\{\mathbf{R}_{\pi(1)}, \mathbf{R}_{\pi(2)}, \ldots, \mathbf{R}_{\pi(h)}\right\}$.

Step 6: If IS new $_{\text {neld, }} \neq$ let $\mathbf{H}_{\text {old }}:=\mathbf{H}_{\text {new }}$ and $\mathbf{C V}_{\mathbf{H}_{\text {old }}}:=\mathbf{C V}_{\mathbf{H}_{\text {new }}}$, compute $\overline{\mathbf{R}}_{\mathbf{H}_{\text {new }}}$ and let $\overline{\mathbf{R}}_{\mathbf{H}_{\text {old }}}:=\overline{\mathbf{R}}_{\mathbf{H}_{\text {new }}}$ and go back to step (3). Else, the process is stopped.

The DRGP(ISE) consists of two steps, whereby in the first step, the suspected HLPs are determined using RMD based on ISE. The suspected HLPs will be placed in the ' $\mathrm{D}$ ' set and the remaining in the ' $\mathrm{R}$ ' set The generalized potential $\left(\hat{p}_{i}\right)$ is employed in the second step to check all the suspected HLPs; those possessing a low leverage point will be put back to the ' $R$ ' group. This technique si continued 


\section{ROBUST HCCM ESTIMATORS}

until all points of the ' $\mathrm{D}$ ' group have been checked to confirm whether they can be referred as HLPs. The generalized potential is defined as follows:

$$
\hat{p}_{i}=\left\{\begin{array}{cc}
h_{i}^{(-\mathrm{D})} & \text { for } i \in \mathrm{D} \\
\frac{h_{i}^{(-\mathrm{D})}}{1-h_{i}^{(-\mathrm{D})}} & \text { for } i \in \mathrm{R}
\end{array}\right.
$$

The cut-off point for DRGP is given by

$$
c d i=\operatorname{median}\left(\hat{p}_{i}\right)+3 \mathrm{Q}_{n}\left(\hat{p}_{i}\right)
$$

$\mathrm{Q}_{n}$, a pairwise order statistic for all distance proposed by Rousseeuw and Croux (1993), is employed to improve the accuracy of the identification of HLPs and is given by $\mathrm{Q}_{n}=c\left\{\left|x_{i}-x_{j}\right| ;\langle j\}_{(k)}\right.$, where $\mathrm{k}={ }^{h} C_{2} \approx{ }^{h} C_{2} / 4$ and $h=[n / 2]+1$. They make used of $c=2.2219$, as this value will provides $\mathrm{Q}_{n}$ a consistent estimator for Gaussian data. If some identified $\hat{p}_{i}$ did not exceed $c d i$ then the case with the least $\hat{p}_{i}$ will be returned to the estimation subset for re-computation of $\hat{p}_{i}$. The values of generalized potential based on the final 'D' set is the DRGP(ISE) represented by $\hat{p}_{i}$ and the ' $\mathrm{D}$ ' points will be declared as HLPs. Following Furno (1996), the DRGP(ISE) weight can be obtained as follows:

$$
w_{i d}=\min \left(1, c d i / \hat{p}_{i}\right)
$$

where the HLPs are weighted by $\left(c d i / \hat{p}_{i}\right)$ and non-leverage by 1 . We also replace equation (7) by (15) and employ RHCCM estimation methods discussed above to obtain the RHCCM estimator based on DRGP(ISE) weighting method denoted by

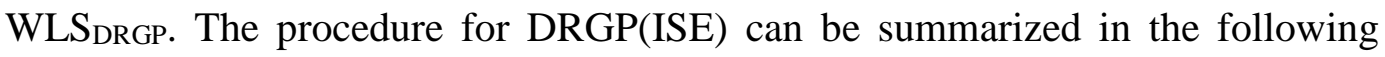
steps:

Step 1: For every $i^{\text {th }}$ point, use the ISE method to compute the $\operatorname{RMD}_{i}$.

Step 2: Any $i^{\text {th }}$ case having $\operatorname{RMD}_{i}>\operatorname{median}\left(\mathrm{RMD}_{i}\right)+3 \mathrm{MAD}(\mathrm{RMD} i)$ is suspected to be HLP and is assigned to the deletion set (D); the other (remaining) cases are put into the set $\mathrm{R}$.

Step 3: Compute $\hat{p}_{i}$ as defined in equation (14) based on the sets $\mathrm{R}$ and $\mathrm{D}$ above. 


\section{MANI ET AL}

Step 4: If all the deleted cases $\hat{p}_{i}>\operatorname{median}\left(\hat{p}_{i}\right)+3 \mathrm{Q}_{n}\left(\hat{p}_{i}\right)$, the respective cases are declared as HLPs. Otherwise, the case with least $\hat{p}_{i}$ will be return to set $\mathrm{R}$ and repeat steps (3) and (4) until all $\hat{p}_{i}>\operatorname{median}\left(\hat{p}_{i}\right)+3 \mathrm{Q}_{n}\left(\hat{p}_{i}\right)$

\section{Simulation Study}

A Monte Carlo simulation is used to assess the performance of the proposed methods under a heteroscedasticity of unknown form in a linear regression model. Following the simulation procedure used by Lima et al. (2009), we consider a linear relation $y_{i}=\beta_{0}+\beta_{1} x_{i 1}+\beta_{2} x_{i 2}+\beta_{3} x_{i 3}+\varepsilon_{i}, i=1,2, \ldots, n$. Three explanatory variables $\left(x_{1}, x_{2}, x_{3}\right)$ are generated from a standard normal distribution in which the true parameters were set at $\beta_{0}=\beta_{1}=\beta_{2}=\beta_{3}=1$ and $\varepsilon_{\mathrm{i}} \sim \mathrm{N}\left(0, \sigma_{i}{ }^{2}\right)$. The strength (degree) of heteroscedasticity is measured by $\lambda=\max \left(\sigma_{i}^{2}\right) / \min \left(\sigma_{i}^{2}\right)$. Three sample sizes ( $n=25,50$, and 100) were replicated twice to form sample sizes of 50,100, and 200 , respectively. The skedastic function is defined as $\sigma_{i}^{2}=\exp \left\{c_{1} x_{i 1}\right\}$ (Lima et al., 2009) where the value of $c_{1}=0.450$ was chosen such that $\lambda \approx 43$ and will be constant among the sample sizes. The value of $\lambda$ indicates the degree of the heteroscedasticity in the data, whereby for homoscedasticity the value of $\lambda=1$. For each of $x_{i} \sim \mathrm{N}(0,1)$, a certain percentage of HLPs were replaced randomly with $\mathrm{N}(20,1)$ at $5 \%, 10 \%$, and $20 \%$ contamination levels for all the sample sizes considered at the average of 10,000 replications.

Shown in Table 1 is the performance of the proposed and existing methods in a clean simulated heteroscedastic data. Presented in Tables 2-4 are the results of both proposed and existing methods for heteroscedastic data with HLP contamination. The tables indicate, in the presence of clean heteroscedastic data, all methods are reasonably closed to each other. However, in the presence of HLPs,

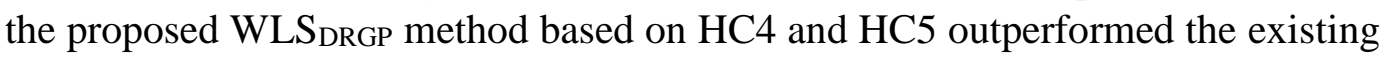
methods as evident by having the smallest standard error of estimate. The WLS DRGP also provides the coefficient of estimates that is closest to the true coefficient. The results which are based on $\mathrm{HC} 4$ are fairly close to the results which are based on HC5. The standard error of the estimates will only be good and efficient when the form of heteroscedasticity is known. In this case, when the structure of heteroscedasticity is unknown, the estimation will lie on the HCCM estimator based on the two methods employed, $\mathrm{HC} 4$ and $\mathrm{HC} 5$, in which their results are very close to each other. The standard error of WLS $S_{\mathrm{DRGP}}$ is the smallest. followed by WLS $\mathrm{RMD}_{\text {, }}$ WLS $_{\mathrm{F}}$, and OLS for a heteroscedastic model in the presence of HLPs in the data set. The result can be seen clearly from the \% reduction of standard errors exhibited 


\section{ROBUST HCCM ESTIMATORS}

in the tables that our proposed methods consistently have the highest reduction of standard errors irrespective of sample sizes and contamination levels.

Table 1. Regression estimates of the simulated data for $n=200, \lambda=43$

\begin{tabular}{|c|c|c|c|c|c|c|}
\hline \multirow[b]{2}{*}{ Con. Level } & & & \multirow{2}{*}{$\begin{array}{r}\text { Coefficient } \\
\text { of estimates }\end{array}$} & \multirow{2}{*}{$\begin{array}{r}\text { Standard error } \\
\text { of estimates }\end{array}$} & \multicolumn{2}{|c|}{ Standard error } \\
\hline & \multicolumn{2}{|c|}{ Estimator } & & & HC4 & HC5 \\
\hline \multirow[t]{16}{*}{$0 \%$ HLPs } & OLS & $b_{0}$ & 1.0007 & 0.1613 & 0.1582 & 0.1643 \\
\hline & & $b_{1}$ & 1.0013 & 0.1658 & 0.1576 & 0.1625 \\
\hline & & $b_{2}$ & 0.9991 & 0.1668 & 0.1604 & 0.1639 \\
\hline & & $b_{3}$ & 1.0012 & 0.1669 & 0.1610 & 0.1626 \\
\hline & $W L S_{F}$ & $b_{0}$ & 1.0008 & 0.1611 & 0.1599 & 0.1659 \\
\hline & & $b_{1}$ & 1.0018 & 0.1708 & 0.1634 & 0.1634 \\
\hline & & $b_{2}$ & 0.9990 & 0.1718 & 0.1668 & 0.1668 \\
\hline & & $b_{3}$ & 1.0014 & 0.1719 & 0.1673 & 0.1663 \\
\hline & WLS $S_{R M D}$ & $b_{0}$ & 1.0009 & 0.1713 & 0.1626 & 0.1626 \\
\hline & & $b_{1}$ & 1.0016 & 0.1781 & 0.1690 & 0.1640 \\
\hline & & $b_{2}$ & 0.9990 & 0.1791 & 0.1699 & 0.1649 \\
\hline & & $b_{3}$ & 1.0014 & 0.1792 & 0.1704 & 0.1654 \\
\hline & WLSDRGP & $b_{0}$ & 1.0008 & 0.1714 & 0.1621 & 0.1621 \\
\hline & & $b_{1}$ & 1.0013 & 0.1787 & 0.1674 & 0.1634 \\
\hline & & $b_{2}$ & 0.9990 & 0.1799 & 0.1692 & 0.1652 \\
\hline & & $b_{3}$ & 1.0012 & 0.1700 & 0.1697 & 0.1652 \\
\hline
\end{tabular}

Table 2. Regression estimates of the simulated data for $n=50, \lambda=43$

\begin{tabular}{|c|c|c|c|c|c|c|c|c|}
\hline \multirow{3}{*}{$\begin{array}{r}\begin{array}{r}\text { Con. } \\
\text { Level }\end{array} \\
5 \% \text { HLPS }\end{array}$} & \multirow{2}{*}{\multicolumn{2}{|c|}{ Estimator }} & \multirow{2}{*}{$\begin{array}{l}\text { Coeff. of } \\
\text { estimates }\end{array}$} & \multirow{2}{*}{$\begin{array}{r}\text { SE of } \\
\text { estimates }\end{array}$} & \multicolumn{4}{|c|}{ Standard error } \\
\hline & & & & & HC4 & HC5 & HC4 \% red. & HC5 \% red. \\
\hline & \multirow[t]{4}{*}{ OLS } & $b_{0}$ & 0.9477 & 0.3021 & 0.2906 & 0.3130 & - & - \\
\hline & & $b_{1}$ & 0.9287 & 0.2658 & 0.2740 & 0.3044 & - & - \\
\hline & & $b_{2}$ & 0.9404 & 0.2558 & 0.2531 & 0.2810 & - & - \\
\hline & & $b_{3}$ & 0.9440 & 0.2561 & 0.2542 & 0.2836 & - & - \\
\hline & \multirow[t]{4}{*}{$W L S_{F}$} & $b_{0}$ & 0.9866 & 0.2254 & 0.2228 & 0.2228 & 23.3495 & 28.8235 \\
\hline & & $b_{1}$ & 0.9716 & 0.2370 & 0.2398 & 0.2398 & 12.9496 & 41.7297 \\
\hline & & $b_{2}$ & 0.9816 & 0.2269 & 0.2265 & 0.2265 & 10.5197 & 40.5483 \\
\hline & & $b_{3}$ & 0.9820 & 0.2275 & 0.2289 & 0.2290 & 9.9175 & 40.3043 \\
\hline & \multirow[t]{4}{*}{$W^{\prime} S_{\text {RMD }}$} & $b_{0}$ & 0.9919 & 0.2080 & 0.2058 & 0.2059 & 29.1684 & 34.2240 \\
\hline & & $b_{1}$ & 0.9891 & 0.2109 & 0.2174 & 0.2174 & 21.4390 & 47.4040 \\
\hline & & $b_{2}$ & 0.9889 & 0.2010 & 0.2036 & 0.2037 & 19.5464 & 46.5320 \\
\hline & & $b_{3}$ & 0.9836 & 0.2015 & 0.2048 & 0.2049 & 19.4148 & 46.5873 \\
\hline & \multirow[t]{4}{*}{ WLS } & $b_{0}$ & 0.9983 & 0.1812 & 0.1833 & 0.1833 & 36.9103 & 41.4163 \\
\hline & & $b_{1}$ & 0.9978 & 0.1972 & 0.1912 & 0.1912 & 31.3409 & 54.0439 \\
\hline & & $b_{2}$ & 0.9977 & 0.1876 & 0.1837 & 0.1837 & 27.4254 & 51.7841 \\
\hline & & $b_{3}$ & 0.9991 & 0.1883 & 0.1854 & 0.1854 & 27.0480 & 51.6593 \\
\hline
\end{tabular}


MANI ET AL

Table 2 (continued).

\begin{tabular}{|c|c|c|c|c|c|c|c|c|}
\hline \multirow{2}{*}{$\begin{array}{l}\text { Con. } \\
\text { Level }\end{array}$} & \multirow{2}{*}{\multicolumn{2}{|c|}{ Estimator }} & \multirow{2}{*}{$\begin{array}{r}\text { Coeff. of } \\
\text { estimates }\end{array}$} & \multirow{2}{*}{$\begin{array}{r}\text { SE of } \\
\text { estimates }\end{array}$} & \multicolumn{4}{|c|}{ Standard error } \\
\hline & & & & & HC4 & HC5 & HC4 \% red. & HC5 \% red. \\
\hline \multirow[t]{16}{*}{$10 \% \mathrm{HLPs}$} & OLS & $b_{0}$ & 0.9468 & 0.3142 & 0.3063 & 0.3011 & - & - \\
\hline & & $b_{1}$ & 0.9104 & 0.2661 & 0.2611 & 0.2619 & - & - \\
\hline & & $b_{2}$ & 0.9048 & 0.2567 & 0.2515 & 0.2514 & - & - \\
\hline & & $b_{3}$ & 0.8926 & 0.2561 & 0.2504 & 0.2510 & - & - \\
\hline & $W_{L} S_{F}$ & $b_{0}$ & 0.9736 & 0.2380 & 0.2258 & 0.2258 & 26.2968 & 25.0285 \\
\hline & & $b_{1}$ & 0.9703 & 0.2330 & 0.2312 & 0.2342 & 11.8895 & 10.9897 \\
\hline & & $b_{2}$ & 0.9724 & 0.2235 & 0.2217 & 0.2247 & 11.8381 & 10.6380 \\
\hline & & $b_{3}$ & 0.9700 & 0.2229 & 0.2216 & 0.2236 & 11.4785 & 10.8940 \\
\hline & $W_{\text {RSD }}$ & $b_{0}$ & 0.9728 & 0.2149 & 0.2132 & 0.2132 & 30.4037 & 29.2060 \\
\hline & & $b_{1}$ & 0.9734 & 0.2251 & 0.2246 & 0.2246 & 14.5361 & 14.8183 \\
\hline & & $b_{2}$ & 0.9721 & 0.2158 & 0.2126 & 0.2126 & 15.4513 & 15.4444 \\
\hline & & $b_{3}$ & 0.9785 & 0.2150 & 0.2115 & 0.2115 & 15.5345 & 15.7371 \\
\hline & $W_{\text {DRGP }}$ & $b_{0}$ & 0.9931 & 0.1925 & 0.1880 & 0.1880 & 38.6319 & 37.5758 \\
\hline & & $b_{1}$ & 0.9900 & 0.2050 & 0.1980 & 0.1980 & 25.1278 & 25.3751 \\
\hline & & $b_{2}$ & 0.9962 & 0.1959 & 0.1884 & 0.1884 & 25.0729 & 25.0667 \\
\hline & & $b_{3}$ & 0.9995 & 0.1948 & 0.1861 & 0.1861 & 25.6627 & 25.8410 \\
\hline \multirow[t]{16}{*}{$20 \%$ HLPs } & OLS & $b_{0}$ & 0.9199 & 0.3345 & 0.3263 & 0.3308 & - & - \\
\hline & & $b_{1}$ & 0.8432 & 0.2859 & 0.2709 & 0.2879 & - & - \\
\hline & & $b_{2}$ & 0.7903 & 0.2761 & 0.2510 & 0.2661 & - & - \\
\hline & & $b_{3}$ & 0.8678 & 0.2767 & 0.2517 & 0.2671 & - & - \\
\hline & $W_{L} S_{F}$ & $b_{0}$ & 0.9760 & 0.2522 & 0.2288 & 0.2288 & 29.8802 & 30.8276 \\
\hline & & $b_{1}$ & 0.9716 & 0.2550 & 0.2527 & 0.2527 & 14.6493 & 19.8747 \\
\hline & & $b_{2}$ & 0.9713 & 0.2450 & 0.2234 & 0.2234 & 11.0042 & 16.0615 \\
\hline & & $b_{3}$ & 0.9706 & 0.2459 & 0.2244 & 0.2244 & 10.8522 & 15.9935 \\
\hline & $\mathrm{WLS}_{\mathrm{RMD}}$ & $b_{0}$ & 0.9724 & 0.2373 & 0.2161 & 0.2161 & 33.7858 & 34.6805 \\
\hline & & $b_{1}$ & 0.9725 & 0.2459 & 0.2262 & 0.2262 & 17.1431 & 22.2158 \\
\hline & & $b_{2}$ & 0.9728 & 0.2360 & 0.2152 & 0.2152 & 14.2775 & 19.1488 \\
\hline & & $b_{3}$ & 0.9710 & 0.2366 & 0.2158 & 0.2158 & 14.2465 & 19.1919 \\
\hline & WLS $_{\text {DRGP }}$ & $b_{0}$ & 0.9956 & 0.1972 & 0.1806 & 0.1806 & 44.6654 & 45.4131 \\
\hline & & $b_{1}$ & 0.9905 & 0.2037 & 0.1978 & 0.1978 & 28.0204 & 32.4272 \\
\hline & & $b_{2}$ & 0.9906 & 0.1939 & 0.1824 & 0.1824 & 27.3150 & 31.4454 \\
\hline & & $b_{3}$ & 0.9897 & 0.1943 & 0.1829 & 0.1829 & 27.3248 & 31.5160 \\
\hline
\end{tabular}

Note: $b_{0}, b_{1}, b_{2}$, and $b_{3}$ are the estimates and $\%$ red. indicates the percentage improvement of the corresponding method over the OLS method; that is why the OLS rows are blank for \% reduction 


\section{ROBUST HCCM ESTIMATORS}

Table 3. Regression estimates of the simulated data for $n=100, \lambda=43$

\begin{tabular}{|c|c|c|c|c|c|c|c|c|}
\hline \multirow{2}{*}{$\begin{array}{l}\text { Con. } \\
\text { Level }\end{array}$} & \multirow{2}{*}{\multicolumn{2}{|c|}{ Estimator }} & \multirow{2}{*}{$\begin{array}{r}\text { Coeff. of } \\
\text { estimates }\end{array}$} & \multirow{2}{*}{$\begin{array}{r}\text { SE of } \\
\text { estimates }\end{array}$} & \multicolumn{4}{|c|}{ Standard error } \\
\hline & & & & & HC4 & HC5 & HC4 \% red. & HC5 \% red. \\
\hline \multirow[t]{16}{*}{$5 \% \mathrm{HLPs}$} & OLS & $b_{0}$ & 0.9439 & 0.1770 & 0.1430 & 0.1440 & - & - \\
\hline & & $b_{1}$ & 0.9375 & 0.1850 & 0.1511 & 0.1506 & - & - \\
\hline & & $b_{2}$ & 0.9477 & 0.1748 & 0.1458 & 0.1442 & - & - \\
\hline & & $b_{3}$ & 0.9476 & 0.1745 & 0.1459 & 0.1442 & - & - \\
\hline & $W_{L} S_{F}$ & $b_{0}$ & 0.9881 & 0.1508 & 0.1206 & 0.1206 & 15.6307 & 16.2319 \\
\hline & & $b_{1}$ & 0.9824 & 0.1665 & 0.1320 & 0.1320 & 13.5382 & 13.2177 \\
\hline & & $b_{2}$ & 0.9897 & 0.1562 & 0.1265 & 0.1265 & 13.2387 & 12.2865 \\
\hline & & $b_{3}$ & 0.9707 & 0.1559 & 0.1265 & 0.1265 & 13.3019 & 12.3180 \\
\hline & $\mathrm{WLS}_{\mathrm{RMD}}$ & $b_{0}$ & 0.9808 & 0.1378 & 0.1118 & 0.1118 & 21.7814 & 22.3388 \\
\hline & & $b_{1}$ & 0.9831 & 0.1531 & 0.1254 & 0.1254 & 18.1884 & 17.8851 \\
\hline & & $b_{2}$ & 0.9834 & 0.1429 & 0.1185 & 0.1185 & 18.6717 & 17.7791 \\
\hline & & $b_{3}$ & 0.9824 & 0.1426 & 0.1186 & 0.1186 & 18.6788 & 17.7560 \\
\hline & $W_{L} S_{D R G P}$ & $b_{0}$ & 0.9974 & 0.1269 & 0.0862 & 0.0862 & 39.7108 & 40.1404 \\
\hline & & $b_{1}$ & 0.9978 & 0.1432 & 0.1169 & 0.1169 & 24.2198 & 23.9389 \\
\hline & & $b_{2}$ & 0.9979 & 0.1331 & 0.1048 & 0.1048 & 28.1038 & 27.3147 \\
\hline & & $b_{3}$ & 0.9977 & 0.1329 & 0.1051 & 0.1051 & 27.9511 & 27.1335 \\
\hline \multirow[t]{16}{*}{$10 \%$ HLPs } & OLS & $b_{0}$ & 0.9281 & 0.2192 & 0.1584 & 0.1591 & - & - \\
\hline & & $b_{1}$ & 0.8713 & 0.2667 & 0.1567 & 0.1572 & - & - \\
\hline & & $b_{2}$ & 0.9050 & 0.2166 & 0.1569 & 0.1508 & - & - \\
\hline & & $b_{3}$ & 0.9081 & 0.2169 & 0.1569 & 0.1507 & - & - \\
\hline & $W_{L} S_{F}$ & $b_{0}$ & 0.9970 & 0.1682 & 0.1242 & 0.1242 & 21.5785 & 21.8933 \\
\hline & & $b_{1}$ & 0.9808 & 0.1745 & 0.1286 & 0.1286 & 18.5056 & 18.7799 \\
\hline & & $b_{2}$ & 0.9844 & 0.1695 & 0.1255 & 0.1255 & 19.9945 & 16.7447 \\
\hline & & $b_{3}$ & 0.9878 & 0.1697 & 0.1256 & 0.1256 & 19.9786 & 16.7041 \\
\hline & $\mathrm{WLS}_{\mathrm{RMD}}$ & $b_{0}$ & 0.9972 & 0.1437 & 0.1127 & 0.1127 & 28.8414 & 29.1270 \\
\hline & & $b_{1}$ & 0.9863 & 0.1610 & 0.1194 & 0.1194 & 24.5589 & 24.8128 \\
\hline & & $b_{2}$ & 0.9860 & 0.1561 & 0.1188 & 0.1188 & 24.2512 & 21.1744 \\
\hline & & $b_{3}$ & 0.9863 & 0.1563 & 0.1188 & 0.1188 & 24.2660 & 21.1670 \\
\hline & $W_{L} S_{D R G P}$ & $b_{0}$ & 0.9978 & 0.1262 & 0.0916 & 0.0916 & 42.1637 & 42.3959 \\
\hline & & $b_{1}$ & 0.9987 & 0.1360 & 0.1088 & 0.1088 & 31.5746 & 31.8049 \\
\hline & & $b_{2}$ & 0.9971 & 0.1313 & 0.0949 & 0.0949 & 39.5106 & 37.0536 \\
\hline & & $b_{3}$ & 0.9972 & 0.1314 & 0.0949 & 0.0949 & 39.4835 & 37.0072 \\
\hline
\end{tabular}




\section{MANI ET AL}

Table 3 (continued).

\begin{tabular}{|c|c|c|c|c|c|c|c|c|}
\hline \multirow{2}{*}{$\begin{array}{r}\text { Con. } \\
\text { Level }\end{array}$} & \multirow{2}{*}{\multicolumn{2}{|c|}{ Estimator }} & \multirow{2}{*}{$\begin{array}{r}\text { Coeff. of } \\
\text { estimates }\end{array}$} & \multirow{2}{*}{$\begin{array}{r}\text { SE of } \\
\text { estimates }\end{array}$} & \multicolumn{4}{|c|}{ Standard error } \\
\hline & & & & & $\mathrm{HC} 4$ & HC5 & HC4 \% red. & HC5 \% red. \\
\hline \multirow[t]{16}{*}{$20 \%$ HLPs } & OLS & $b_{0}$ & 0.9141 & 0.2940 & 0.1715 & 0.1722 & - & - \\
\hline & & $b_{1}$ & 0.6384 & 0.3155 & 0.1806 & 0.1840 & - & - \\
\hline & & $b_{2}$ & 0.8576 & 0.3107 & 0.1707 & 0.1738 & - & - \\
\hline & & $b_{3}$ & 0.7624 & 0.3105 & 0.1705 & 0.1735 & - & - \\
\hline & $W L S_{F}$ & $b_{0}$ & 0.9787 & 0.1725 & 0.1317 & 0.1317 & 23.1937 & 23.4976 \\
\hline & & $b_{1}$ & 0.9769 & 0.1793 & 0.1425 & 0.1425 & 21.6934 & 23.2176 \\
\hline & & $b_{2}$ & 0.9718 & 0.1745 & 0.1335 & 0.1335 & 21.7786 & 23.1501 \\
\hline & & $b_{3}$ & 0.9718 & 0.1743 & 0.1334 & 0.1334 & 21.7348 & 23.0710 \\
\hline & $W_{\text {RMD }}$ & $b_{0}$ & 0.9871 & 0.1630 & 0.1201 & 0.1201 & 29.9625 & 30.2396 \\
\hline & & $b_{1}$ & 0.9849 & 0.1655 & 0.1336 & 0.1336 & 26.7203 & 28.1467 \\
\hline & & $b_{2}$ & 0.9803 & 0.1606 & 0.1279 & 0.1279 & 25.0967 & 26.4101 \\
\hline & & $b_{3}$ & 0.9799 & 0.1604 & 0.1274 & 0.1274 & 25.2752 & 26.5509 \\
\hline & $W_{\text {LRGP }}$ & $b_{0}$ & 0.9981 & 0.1333 & 0.1201 & 0.1042 & 29.9625 & 39.4910 \\
\hline & & $b_{1}$ & 0.9980 & 0.1439 & 0.1336 & 0.1126 & 26.7203 & 39.8862 \\
\hline & & $b_{2}$ & 0.9936 & 0.1390 & 0.1279 & 0.1051 & 25.0967 & 39.5181 \\
\hline & & $b_{3}$ & 0.9925 & 0.1388 & 0.1274 & 0.1047 & 25.2752 & 39.6350 \\
\hline
\end{tabular}

Note: $b_{0}, b_{1}, b_{2}$, and $b_{3}$ are the estimates and \% red. indicates the percentage improvement of the corresponding method over the OLS method; that is why the OLS rows are blank for \% reduction

Table 4. Regression estimates of the simulated data for $n=200, \lambda=43$

\begin{tabular}{|c|c|c|c|c|c|c|c|c|}
\hline \multirow{2}{*}{$\begin{array}{l}\text { Con. } \\
\text { Level }\end{array}$} & \multirow{2}{*}{\multicolumn{2}{|c|}{ Estimator }} & \multirow{2}{*}{$\begin{array}{r}\text { Coeff. of } \\
\text { estimates }\end{array}$} & \multirow{2}{*}{$\begin{array}{r}\text { SE of } \\
\text { estimates }\end{array}$} & \multicolumn{4}{|c|}{ Standard error } \\
\hline & & & & & HC4 & HC5 & HC4 \% red. & HC5 \% red. \\
\hline \multirow[t]{16}{*}{$5 \%$ HLPs } & OLS & $b_{0}$ & 0.9481 & 0.1750 & 0.1456 & 0.1461 & - & - \\
\hline & & $b_{1}$ & 0.8214 & 0.1794 & 0.1488 & 0.1490 & - & - \\
\hline & & $b_{2}$ & 0.9122 & 0.1719 & 0.1431 & 0.1476 & - & - \\
\hline & & $b_{3}$ & 0.9146 & 0.1718 & 0.1438 & 0.1482 & - & - \\
\hline & $W_{F}$ & $b_{0}$ & 0.9746 & 0.1421 & 0.1252 & 0.1252 & 13.9818 & 14.2649 \\
\hline & & $b_{1}$ & 0.9678 & 0.1508 & 0.1340 & 0.1340 & 10.2815 & 10.4046 \\
\hline & & $b_{2}$ & 0.9723 & 0.1438 & 0.1293 & 0.1293 & 9.6916 & 12.4048 \\
\hline & & $b_{3}$ & 0.9727 & 0.1435 & 0.1297 & 0.1297 & 9.7932 & 12.4811 \\
\hline & $W_{L} S_{R M D}$ & $b_{0}$ & 0.9855 & 0.1368 & 0.1108 & 0.1108 & 23.8683 & 24.1189 \\
\hline & & $b_{1}$ & 0.9802 & 0.1448 & 0.1176 & 0.1176 & 21.6724 & 21.7799 \\
\hline & & $b_{2}$ & 0.9840 & 0.1396 & 0.1107 & 0.1107 & 22.6745 & 24.9976 \\
\hline & & $b_{3}$ & 0.9855 & 0.1396 & 0.1122 & 0.1122 & 21.9857 & 24.3103 \\
\hline & $W_{L} S_{D R G P}$ & $b_{0}$ & 0.9972 & 0.1128 & 0.0920 & 0.0920 & 36.7822 & 36.9903 \\
\hline & & $b_{1}$ & 0.9978 & 0.1136 & 0.1003 & 0.1003 & 33.7470 & 33.8380 \\
\hline & & $b_{2}$ & 0.9985 & 0.1070 & 0.0984 & 0.0984 & 31.2174 & 33.2839 \\
\hline & & $b_{3}$ & 0.9986 & 0.1073 & 0.0998 & 0.0998 & 30.5851 & 32.6534 \\
\hline
\end{tabular}




\section{ROBUST HCCM ESTIMATORS}

Table 4 (continued).

\begin{tabular}{|c|c|c|c|c|c|c|c|c|}
\hline \multirow{3}{*}{$\begin{array}{r}\begin{array}{r}\text { Con. } \\
\text { Level }\end{array} \\
10 \% \text { HLPS }\end{array}$} & \multirow{2}{*}{\multicolumn{2}{|c|}{ Estimator }} & \multirow{2}{*}{$\begin{array}{r}\text { Coeff. of } \\
\text { estimates }\end{array}$} & \multirow{2}{*}{$\begin{array}{r}\text { SE of } \\
\text { estimates }\end{array}$} & \multicolumn{4}{|c|}{ Standard error } \\
\hline & & & & & HC4 & HC5 & HC4 \% red. & HC5 \% red. \\
\hline & OLS & $b_{0}$ & 0.9230 & 0.2287 & 0.1449 & 0.1452 & - & - \\
\hline & & $b_{1}$ & 0.8535 & 0.2358 & 0.1589 & 0.1580 & - & 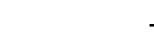 \\
\hline & & $b_{2}$ & 0.8737 & 0.2270 & 0.1458 & 0.1488 & - & 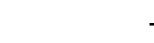 \\
\hline & & $b_{3}$ & 0.7836 & 0.2261 & 0.1469 & 0.1495 & - & 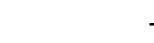 \\
\hline & $W L S_{F}$ & $b_{0}$ & 0.9795 & 0.1542 & 0.1288 & 0.1288 & 11.1246 & 11.3354 \\
\hline & & $b_{1}$ & 0.9660 & 0.1696 & 0.1385 & 0.1385 & 13.7211 & 13.1560 \\
\hline & & $b_{2}$ & 0.9651 & 0.1572 & 0.1273 & 0.1273 & 12.7049 & 14.4391 \\
\hline & & $b_{3}$ & 0.9661 & 0.1599 & 0.1288 & 0.1288 & 12.3139 & 13.8354 \\
\hline & $W L S_{\text {RMD }}$ & $b_{0}$ & 0.9879 & 0.1484 & 0.1228 & 0.1228 & 15.2752 & 15.4761 \\
\hline & & $b_{1}$ & 0.9714 & 0.1546 & 0.1334 & 0.1334 & 17.1485 & 16.6059 \\
\hline & & $b_{2}$ & 0.9716 & 0.1427 & 0.1222 & 0.1222 & 16.1878 & 17.8529 \\
\hline & & $b_{3}$ & 0.9720 & 0.1451 & 0.1229 & 0.1229 & 16.2987 & 17.7510 \\
\hline & WLS & $b_{0}$ & 0.9944 & 0.1277 & 0.1162 & 0.1162 & 19.8140 & 20.0041 \\
\hline & & $b_{1}$ & 0.9917 & 0.1369 & 0.1248 & 0.1248 & 22.9247 & 22.4199 \\
\hline & & $b_{2}$ & 0.9908 & 0.1257 & 0.1186 & 0.1186 & 18.6353 & 20.2517 \\
\hline & & $b_{3}$ & 0.9911 & 0.1272 & 0.1201 & 0.1201 & 18.2379 & 19.6566 \\
\hline $20 \%$ HLPs & OLS & $b_{0}$ & 0.9065 & 0.3662 & 0.1729 & 0.1733 & - & . \\
\hline & & $b_{1}$ & 0.6250 & 0.3334 & 0.1831 & 0.1856 & - & 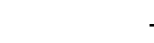 \\
\hline & & $b_{2}$ & 0.7048 & 0.3234 & 0.1747 & 0.1766 & - & 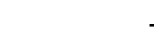 \\
\hline & & $b_{3}$ & 0.7927 & 0.3230 & 0.1748 & 0.1768 & - & 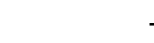 \\
\hline & $W L S_{F}$ & $b_{0}$ & 0.9607 & 0.1940 & 0.1458 & 0.1458 & 15.6485 & 15.8484 \\
\hline & & $b_{1}$ & 0.9650 & 0.2086 & 0.1549 & 0.1549 & 16.3059 & 17.4608 \\
\hline & & $b_{2}$ & 0.9655 & 0.1982 & 0.1466 & 0.1466 & 16.0547 & 16.9728 \\
\hline & & $b_{3}$ & 0.9669 & 0.1978 & 0.1474 & 0.1474 & 15.6639 & 16.5973 \\
\hline & $W^{\prime} S_{\text {RMD }}$ & $b_{0}$ & 0.9775 & 0.1822 & 0.1403 & 0.1403 & 18.8577 & 19.0501 \\
\hline & & $b_{1}$ & 0.9715 & 0.1933 & 0.1504 & 0.1504 & 18.8900 & 20.0092 \\
\hline & & $b_{2}$ & 0.9754 & 0.1836 & 0.1420 & 0.1420 & 18.7135 & 19.6025 \\
\hline & & $b_{3}$ & 0.9785 & 0.1828 & 0.1420 & 0.1420 & 18.7608 & 19.6599 \\
\hline & WLS ${ }_{D R G P}$ & $b_{0}$ & 0.9926 & 0.1634 & 0.1218 & 0.1218 & 29.5194 & 29.6864 \\
\hline & & $b_{1}$ & 0.9919 & 0.1707 & 0.1337 & 0.1337 & 28.5727 & 29.5584 \\
\hline & & $b_{2}$ & 0.9900 & 0.1613 & 0.1244 & 0.1244 & 28.7865 & 29.5654 \\
\hline & & $b_{3}$ & 0.9916 & 0.1607 & 0.1259 & 0.1259 & 27.9588 & 28.7561 \\
\hline
\end{tabular}

Note: $b_{0}, b_{1}, b_{2}$, and $b_{3}$ are the estimates and $\%$ red. indicates the percentage improvement of the corresponding method over the OLS method; that is why the OLS rows are blank for \% reduction

\section{Numerical Examples}

The performance of the proposed WLS DRGP $_{\text {and }}$ WLS $S_{\text {RMD }}$ methods are evaluated using education expenditure data and an artificial heteroscedastic data set. Firstly, consider education expenditure data taken from Chatterjee and Hadi (2006). It 


\section{MANI ET AL}

represents the relationship between per capita income on an education project from 1975 and three independent variables, namely per capita income in $1973\left(x_{1}\right)$, number of residents per thousands under 18 years of age $\left(x_{2}\right)$, and number of residents per thousands under 18 years of age in $1974\left(x_{3}\right)$. The existing methods (OLS and $\mathrm{WLS}_{\mathrm{F}}$ ) and the new proposed methods (WLS $\mathrm{RMD}_{\mathrm{N}}$ and WLS $\mathrm{SRGP}_{\mathrm{D}}$ ) were then applied to the data. The data were modified by introducing HLP contamination, in which the $2^{\text {nd }}, 27^{\text {th }}$, and $40^{\text {th }}$ observations were replaced by 1323,817 , and 1605 for $x_{2}, x_{1}, x_{3}$, respectively. As noted in Figures 1 and 2, both data sets have heteroscedastic errors due to the funnel shape produced by the residuals versus fitted values plot.

Shown in Tables 5 and 6 are the results of the education expenditure and modified education expenditure data. The results indicate the proposed WLS $\mathrm{RMD}$

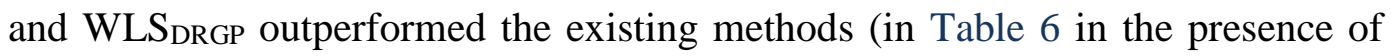
heteroscedasticity and HLPs) by providing very small standard errors and also having equal performances in Table 5, in situation where only the heteroscedasticity problem is present. The WLS $\mathrm{S}_{\text {DRGP }}$ based on both HC4 and HC5 immediately appears to be the best of all the estimators by possessing the highest percentage of reduction from the OLS.

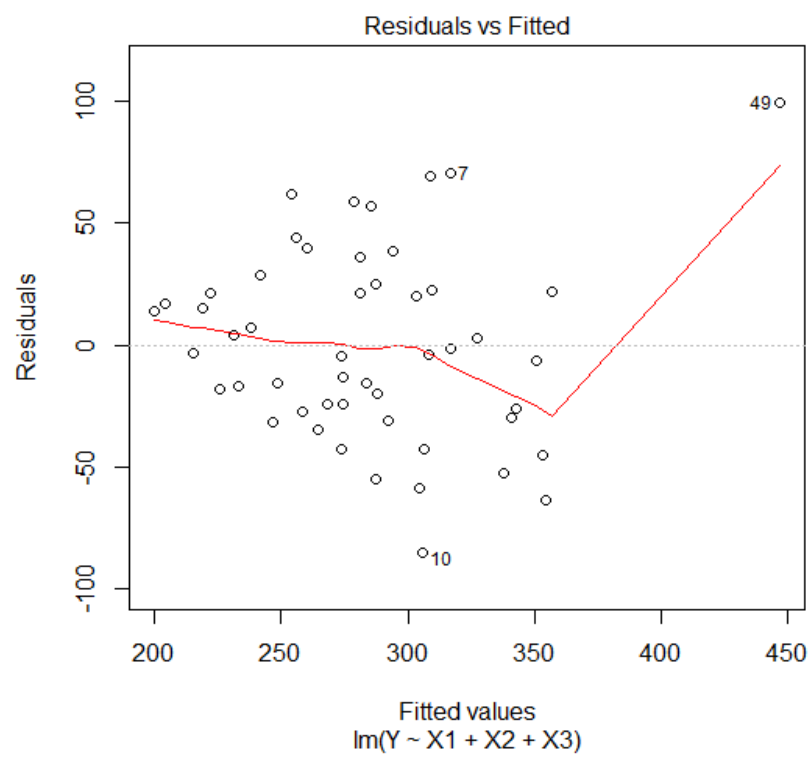

Figure 1. Plot of OLS residuals versus fitted values for education expenditure data 


\section{ROBUST HCCM ESTIMATORS}

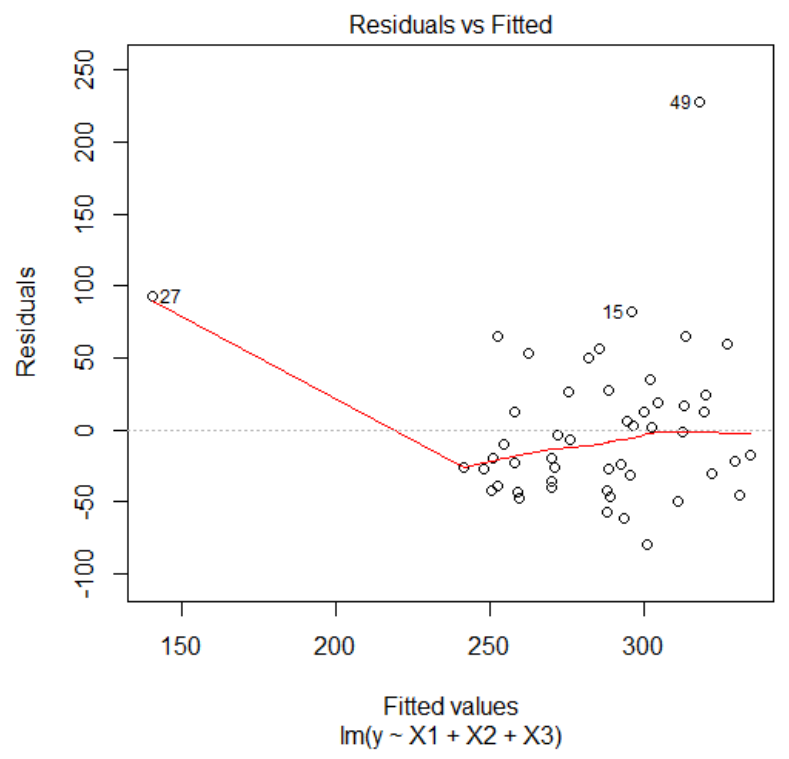

Figure 2. Plot of OLS residuals versus fitted values for modified educational expenditure data

Table 5. Regression estimates for the education expenditure data set

\begin{tabular}{|c|c|c|c|c|c|c|c|}
\hline \multirow{2}{*}{\multicolumn{2}{|c|}{ Estimator }} & \multirow{2}{*}{$\begin{array}{r}\text { Coeff. of } \\
\text { estimates }\end{array}$} & \multirow{2}{*}{$\begin{array}{r}\text { SE of } \\
\text { estimates }\end{array}$} & \multicolumn{4}{|c|}{ Standard error } \\
\hline & & & & HC4 & HC5 & HC4 \% red. & HC5 \% red. \\
\hline \multirow[t]{4}{*}{ OLS } & $b_{0}$ & -556.5680 & 123.1953 & 102.3823 & 13.7623 & - & - \\
\hline & $b_{1}$ & 0.0724 & 0.0116 & 0.0180 & 0.0254 & - & - \\
\hline & $b_{2}$ & 1.5521 & 0.3147 & 0.4765 & 0.1948 & - & - \\
\hline & $b_{3}$ & -0.0043 & 0.0514 & 0.0623 & 0.1598 & - & - \\
\hline \multirow[t]{4}{*}{$W L S_{F}$} & $b_{0}$ & -375.7503 & 135.7155 & 0.0002 & 0.0002 & 99.9998 & 99.9706 \\
\hline & $b_{1}$ & 0.0591 & 0.0122 & 0.0124 & 0.0110 & 30.7942 & 53.7723 \\
\hline & $b_{2}$ & 1.1023 & 0.3502 & 0.0943 & 0.0933 & 80.2057 & 53.6256 \\
\hline & $b_{3}$ & 0.0337 & 0.0528 & 0.0517 & 0.0617 & 15.0874 & 57.6411 \\
\hline \multirow[t]{4}{*}{ WLSRMD } & $b_{0}$ & -485.2476 & 129.2253 & 0.0002 & 0.0002 & 99.9998 & 99.9703 \\
\hline & $b_{1}$ & 0.0673 & 0.0120 & 0.0118 & 0.0118 & 34.0634 & 56.3332 \\
\hline & $b_{2}$ & 1.3749 & 0.3331 & 0.0934 & 0.0924 & 80.3954 & 54.0359 \\
\hline & $b_{3}$ & 0.0096 & 0.0525 & 0.0643 & 0.0543 & 15.2662 & 59.7461 \\
\hline \multirow[t]{4}{*}{ WLSDRGP } & $b_{0}$ & -388.7580 & 134.6718 & 0.0002 & 0.0002 & 99.9998 & 99.9706 \\
\hline & $b_{1}$ & 0.0609 & 0.0122 & 0.0103 & 0.0105 & 42.4586 & 58.4868 \\
\hline & $b_{2}$ & 1.1327 & 0.3493 & 0.0907 & 0.0907 & 80.9705 & 56.4428 \\
\hline & $b_{3}$ & 0.0260 & 0.0528 & 0.0518 & 0.0508 & 16.9311 & 68.2448 \\
\hline
\end{tabular}

Note: $b_{0}, b_{1}, b_{2}$, and $b_{3}$ are the estimates and $\%$ red. indicates the percentage improvement of the corresponding method over the OLS method; that is why the OLS rows are blank for \% reduction 


\section{MANI ET AL}

Table 6. Regression estimates for the modified education expenditure data set

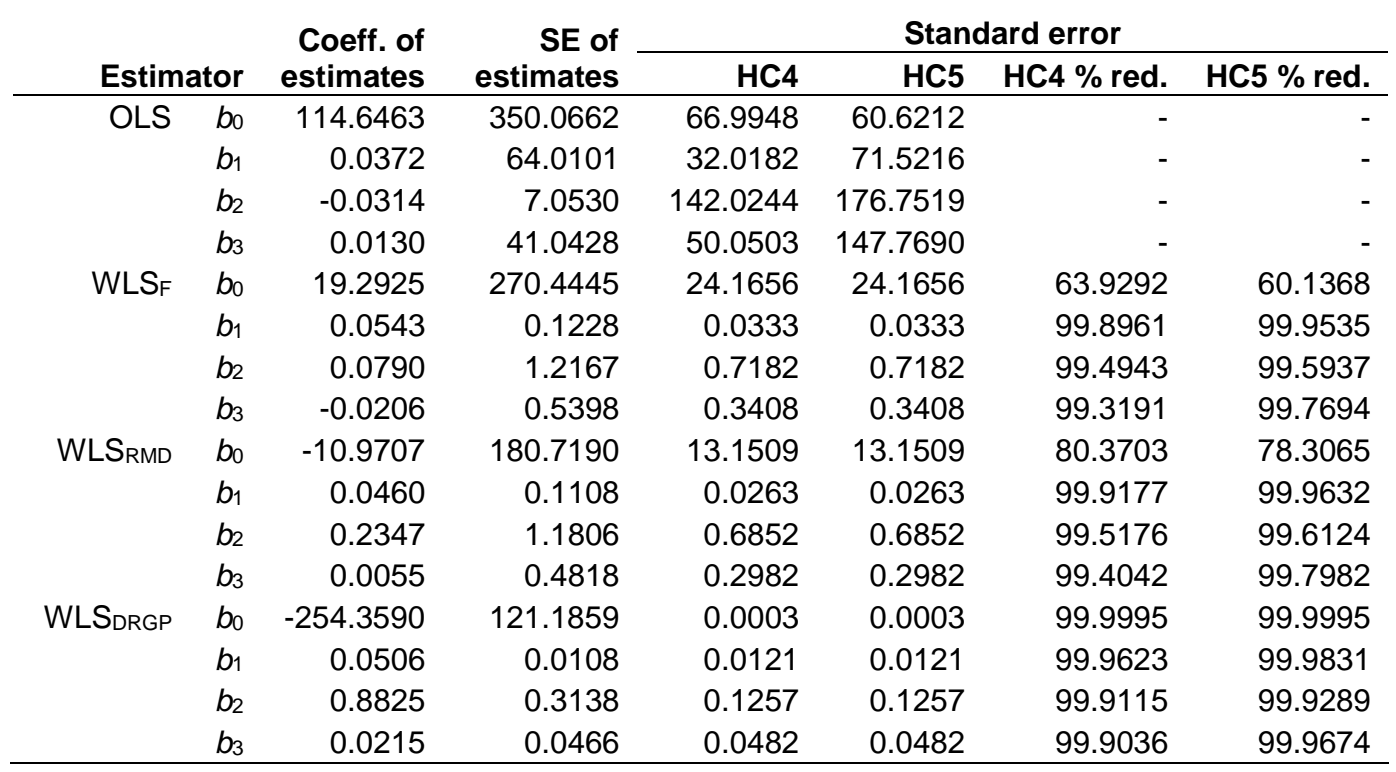

Note: $b_{0}, b_{1}, b_{2}$, and $b_{3}$ are the estimates and \% red. indicates the percentage improvement of the corresponding method over the OLS method; that is why the OLS rows are blank for \% reduction

Secondly, an artificial heteroscedastic dataset of 100 observations were generated, where the explanatory and response variables were generated from yjr normal distribution $\mathrm{N}(20,1)$ and $y_{i}=1+x_{i 1}+x_{i 2}+x_{i 3}+\varepsilon_{i}$, respectively. The heteroscedasticity was created in the same way as above, and the data was modified by introducing HLPs such that the $1^{\text {st }}, 15^{\text {th }}$, and $70^{\text {th }}$ observations were replaced by 41.0028, 40.6902, and 8.9320 for $x_{1}, x_{3}, x_{2}$, respectively. Both of Figures 3 and 4 show the presence of heteroscedasticity in the data due the funnel shape produced in the plots.

Presented in Tables 7 and 8 are the results of the artificial data and modified artificial data set, respectively. It can be observed from Table 7 that all estimators are equally good in the clean data set. Nonetheless, the OLS is much affected by HLPs, followed by the WLS $\mathrm{F}$ and WLS $\mathrm{RMD}$.

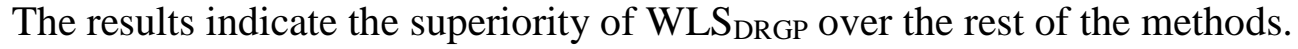
It can be concluded the WLS DRGP $_{\text {is better and more efficient then WLS }}$ RMD, WLS and OLS in the estimation of heteroscedastic models in the presence of HLPs in a data set. As further research, we recommend investigating how this proposed methods work for both Type-I and Type-II errors using the quasi- $t$ statistic. 


\section{ROBUST HCCM ESTIMATORS}

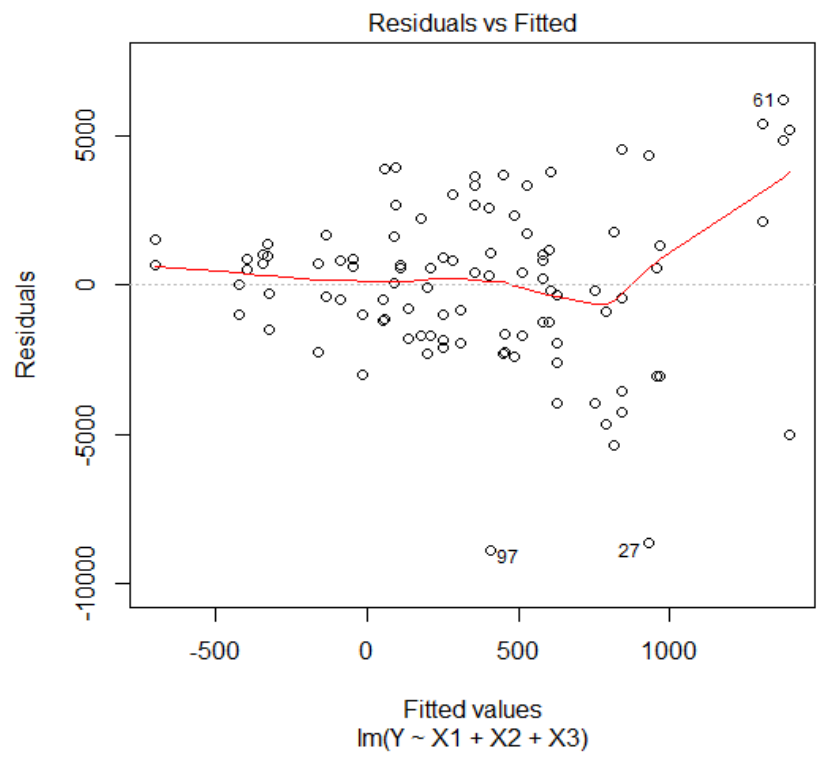

Figure 3. Plot of OLS residuals versus fitted values for artificial data

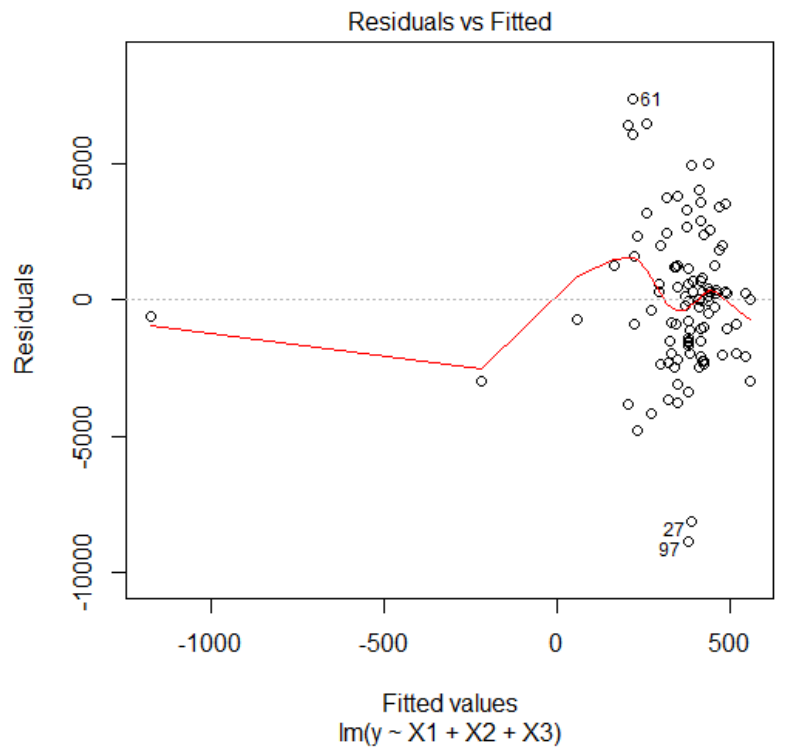

Figure 4. Plot of OLS residuals versus fitted values for modified artificial data 


\section{MANI ET AL}

Table 7. Regression estimates for the artificial data set

\begin{tabular}{|c|c|c|c|c|c|c|c|}
\hline & & \multirow{2}{*}{$\begin{array}{r}\text { Coeff. of } \\
\text { estimates }\end{array}$} & \multirow{2}{*}{$\begin{array}{r}\text { SE of } \\
\text { estimates }\end{array}$} & \multicolumn{4}{|c|}{ Standard error } \\
\hline \multicolumn{2}{|c|}{ Estimator } & & & HC4 & HC5 & HC4 \% red. & HC5 \% red. \\
\hline \multirow[t]{4}{*}{ OLS } & $b_{0}$ & -5911.0888 & 9747.9701 & 1876.5408 & 1810.5194 & - & - \\
\hline & $b_{1}$ & 418.6609 & 351.5534 & 327.1687 & 369.4983 & - & - \\
\hline & $b_{2}$ & -70.8100 & 426.8935 & 341.5515 & 352.7552 & - & - \\
\hline & $b_{3}$ & -39.0783 & 394.3772 & 372.5343 & 383.8704 & - & - \\
\hline \multirow[t]{4}{*}{$W_{L} S_{F}$} & $b_{0}$ & -2852.0091 & 9057.6309 & 1469.6061 & 1469.6061 & 21.6854 & 18.8296 \\
\hline & $b_{1}$ & 304.5275 & 350.0965 & 302.9163 & 302.9163 & 7.4128 & 18.0196 \\
\hline & $b_{2}$ & -141.4352 & 416.5253 & 305.9416 & 305.9416 & 10.4259 & 13.2708 \\
\hline & $b_{3}$ & -9.3324 & 384.7349 & 324.7982 & 324.7982 & 12.8139 & 12.3886 \\
\hline \multirow[t]{4}{*}{$W_{L S}$} & $b_{0}$ & -5911.0888 & 8747.9732 & 1410.5194 & 1410.5194 & 24.8341 & 22.0931 \\
\hline & $b_{1}$ & 418.6609 & 346.5534 & 281.4983 & 281.4983 & 13.9593 & 23.8161 \\
\hline & $b_{2}$ & -70.8100 & 406.8935 & 302.7552 & 302.7552 & 11.3588 & 14.1741 \\
\hline & $b_{3}$ & -39.0783 & 364.3772 & 333.8704 & 333.8704 & 13.0629 & 13.0252 \\
\hline \multirow[t]{4}{*}{$W_{\text {DRGP }}$} & $b_{0}$ & -5911.0888 & 8707.9711 & 1410.5194 & 1410.5194 & 24.8341 & 22.0931 \\
\hline & $b_{1}$ & 418.6609 & 331.5534 & 279.4983 & 279.4983 & 14.5706 & 24.3574 \\
\hline & $b_{2}$ & -70.8100 & 401.8935 & 292.7552 & 292.7552 & 14.2867 & 17.0090 \\
\hline & $b_{3}$ & -39.0783 & 361.3772 & 321.8704 & 321.8704 & 13.5998 & 16.1513 \\
\hline
\end{tabular}

Note: $b_{0}, b_{1}, b_{2}$, and $b_{3}$ are the estimates and \% red. indicates the percentage improvement of the corresponding method over the OLS method; that is why the OLS rows are blank for \% reduction

Table 8. Regression estimates for the modified artificial data set

\begin{tabular}{|c|c|c|c|c|c|c|c|}
\hline \multirow{2}{*}{\multicolumn{2}{|c|}{ Estimator }} & \multirow{2}{*}{$\begin{array}{r}\text { Coeff. of } \\
\text { estimates }\end{array}$} & \multirow{2}{*}{$\begin{array}{r}\text { SE of } \\
\text { estimates }\end{array}$} & \multicolumn{4}{|c|}{ Standard error } \\
\hline & & & & HC4 & HC5 & HC4 \% red. & HC5 \% red. \\
\hline \multirow[t]{4}{*}{ OLS } & $b_{0}$ & 2347.2014 & 13452.7878 & 4854.3334 & 4180.9672 & - & - \\
\hline & $b_{1}$ & -32.9776 & 318.3895 & 548.5326 & 847.0869 & - & - \\
\hline & $b_{2}$ & -75.1522 & 325.8351 & 558.1543 & 508.2788 & - & - \\
\hline & $b_{3}$ & 10.6393 & 393.9614 & 548.9331 & 756.4859 & - & - \\
\hline \multirow[t]{4}{*}{$W_{L} S_{F}$} & $b_{0}$ & -4202.5395 & 8846.2733 & 2677.4813 & 2677.4813 & 44.8435 & 35.9602 \\
\hline & $b_{1}$ & 322.4820 & 219.3419 & 406.0620 & 436.0620 & 25.9730 & 48.5222 \\
\hline & $b_{2}$ & -56.0296 & 278.6068 & 426.3988 & 426.3988 & 23.6056 & 16.1093 \\
\hline & $b_{3}$ & -38.8055 & 274.4062 & 391.0439 & 391.0439 & 28.7629 & 48.3078 \\
\hline \multirow[t]{4}{*}{ WLS $\mathrm{RMD}$} & $b_{0}$ & -2263.0811 & 8760.7035 & 2243.4518 & 2243.4518 & 53.7846 & 46.3413 \\
\hline & $b_{1}$ & 190.1914 & 187.8816 & 383.4138 & 383.4138 & 30.1019 & 54.7374 \\
\hline & $b_{2}$ & -49.3891 & 227.0691 & 375.6060 & 375.6060 & 32.7057 & 26.1024 \\
\hline & $b_{3}$ & -9.3389 & 239.9932 & 378.1985 & 378.1985 & 31.1030 & 50.0059 \\
\hline \multirow[t]{4}{*}{$W_{\text {DRGP }}$} & $b_{0}$ & -5719.2772 & 8202.9609 & 1463.4209 & 1463.4209 & 69.8533 & 64.9980 \\
\hline & $b_{1}$ & 415.0248 & 155.5852 & 292.8725 & 292.8725 & 46.6080 & 65.4259 \\
\hline & $b_{2}$ & -67.9705 & 203.5646 & 282.0422 & 282.0422 & 49.4688 & 44.5103 \\
\hline & $b_{3}$ & -39.0423 & 216.8809 & 299.3767 & 299.3767 & 45.4621 & 60.4253 \\
\hline
\end{tabular}

Note: $b_{0}, b_{1}, b_{2}$, and $b_{3}$ are the estimates and \% red. indicates the percentage improvement of the corresponding method over the OLS method; that is why the OLS rows are blank for \% reduction 


\section{ROBUST HCCM ESTIMATORS}

\section{Conclusion}

This research provides a better algorithm for estimating model parameters in linear regression when heteroscedasticity and high leverage points exist in a data set. Even though the OLS method provides unbiased estimates in the presence of heteroscedasticity, it is not efficient. The Furno's weighted least squares method based on a leverage weight function is also not efficient enough to remedy the problem of heteroscedastic errors with unknown form and high leverage point. Here, two weighting functions based on RMD and DRGP are proposed to be incorporated in the weighted least squares and Robust HCCM (HC4 and HC5) based estimators.

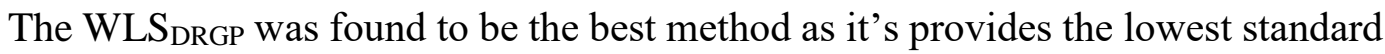
errors of HC4 and HC5, followed by the WLS $\mathrm{RMD}_{\mathrm{WLS}}$, and OLS.

\section{References}

Chatterjee, S., \& Hadi, A. S. (2006). Regression analysis by example (4th ed.). New York: Wiley. doi: 10.1002/0470055464

Cribari-Neto, F. (2004). Asymptotic inference under heteroskedasticity of unknown form. Computational Statistics \& Data Analysis, 45(1), 215-233. doi: 10.1016/s0167-9473(02)00366-3

Cribari-Neto, F., Souza, T. C., \& Vasconcellos, K. L. P. (2007). Inference under heteroskedasticity and leveraged data. Communications in Statistics Theory and Methods, 36(10), 1877-1888. doi: 10.1080/03610920601126589

Cribari-Neto, F., \& Zarkos, S. (1999). Bootstrap methods for heteroskedastic regression models: Evidence on estimation and testing. Econometric Reviews, 18(2), 211-228. doi: 10.1080/07474939908800440

Davidson, R., \& MacKinnon, J. G. (1993). Estimation and inference in econometrics. New York: Oxford University Press.

Furno, M. (1996). Small sample behavior of a robust heteroskedasticity consistent covariance matrix estimator. Journal of Statistical Computation and Simulation, 54(1-3), 115-128. doi: 10.1080/00949659608811723

Furno, M. (1997). A robust heteroskedasticity consistent covariance matrix estimator. A Journal of Theoretical and Applied Statistics, 30(3), 201-219. doi: 10.1080/02331889708802610

Habshah, M., Norazan, M. R., \& Imon, A. H. M. R. (2009). The performance of diagnostic-robust generalized potentials for the identification of 


\section{MANI ET AL}

multiple high leverage points in linear regression. Journal of Applied Statistics, 36(5), 507-520. doi: 10.1080/02664760802553463

Hausman, J., \& Palmer, C. (2011). Heteroskedasticity-robust inference in finite samples. Economics Letters, 116(2), 232-235. doi:

10.1016/j.econlet.2012.02.007

Imon, A. H. M. R. (2002) Identifying multiple high leverage points in linear regression. Journal of Statistical Studies, 3, 207-218.

Leroy, A. M., \& Rousseeuw, P. J. (1987). Robust regression and outlier detection. New York: Wiley.

Lim, H. A., \& Habshah, M. (2016). Diagnostic robust generalized potential based on index set equality (DRGP(ISE)) for the identification of high leverage points in linear models. Computational Statistics, 31(3), 859-877. doi:

10.1007/s00180-016-0662-6

Lima, V. M. C., Souza, T. C., Cribari-Neto, F., \& Fernandes, G. B. (2009). Heteroskedasticity- robust inference in linear regressions. Communications in Statistics - Simulation and Computation, 39(1), 194-206. doi:

10.1080/03610910903402572

Long, J. S., \& Ervin, L. H. (2000). Using heteroscedasticity consistent standard errors in the linear regression model. The American Statistician, 54(3), 217-224. doi: 10.1080/00031305.2000.10474549

MacKinnon, J. G., \& White, H. (1985). Some heteroskedasticity-consistent covariance matrix estimators with improved finite sample properties. Journal of Econometrics, 29(3), 305-325. doi: 10.1016/0304-4076(85)90158-7

Mahalanobis, P. C. (1936). On the generalized distance in statistics. Proceedings of the National Institute of Science, India, 2(1), 49-55.

Peña, D., \& Yohai, V. J. (1995). The detection of influential subsets in linear regression by using an influence matrix. Journal of the Royal Statistical Society. Series B (Methodological), 57(1), 145-156. Available from https://www.jstor.org/stable/2346090

Rana, S., Midi, H., \& Imon, A. H. M. R. (2012). Robust wild bootstrap for stabilizing the variance of parameter estimates in heteroscedastic regression models in the presence of outliers. Mathematical Problems in Engineering, 2012, 730328. doi: 10.1155/2012/730328

Rohayu, M. S. (2013). A robust estimation method of location and scale with application in monitoring process variability (Unpublished doctoral thesis). Universiti Teknologi Malaysia, Malaysia. 


\section{ROBUST HCCM ESTIMATORS}

Rousseeuw, P. J. (1984). Least median of squares regression. Journal of the American Statistical Association, 79(388), 871-880. doi:

10.1080/01621459.1984.10477105

Rousseeuw, P. J., \& Croux, C. (1993). Alternatives to the median absolute deviation. Journal of the American Statistical Association, 88(424), 1273-1283. doi: 10.1080/01621459.1993.10476408

Rousseeuw, P. J., \& Driessen, K. V. (1999) A fast algorithm for the minimum covariance determinant estimator. Technometrics, 41(3), 212-223. doi: 10.1080/00401706.1999.10485670

White, H. (1980). A heteroskedasticity-consistent covariance matrix estimator and a direct test for heteroskedasticity. Econometrica, 48(4), 817-838. doi: $10.2307 / 1912934$ 